\title{
Predictors of medication adherence in pediatric inflammatory bowel disease patients at the Stollery Children's Hospital
}

\author{
L Kitney $M D^{1}$, JM Turner MD PhD ${ }^{1}$, D Spady $M D^{2}$, B Malik BSc${ }^{1}$, \\ W El-Matary MD ${ }^{1}$, R Persad MD ${ }^{1}$, HQ Huynh $M^{1}$
}

\begin{abstract}
L Kitney, JM Turner, D Spady, et al. Predictors of medication adherence in pediatric inflammatory bowel disease patients at the Stollery Children's Hospital. Can J Gastroenterol 2009;23(12):811-815.

BACKGROUND: Patients with inflammatory bowel disease (IBD) often do not take their medications as prescribed.

OBJECTIVE: To examine self-reported adherence rates in IBD patients at the Stollery Children's Hospital (Edmonton, Alberta) and to determine predictors of medication adherence.

METHODS: A survey was mailed to 212 pediatric IBD patients of the Stollery Children's Hospital. A chart review was completed for those who returned the survey.

RESULTS: A total of 119 patients completed the survey. The nonresponders were significantly older than responders ( 14.5 years versus 13.2 years; $\mathrm{P}=0.032$ ). The overall adherence rate was $80 \%$. Nonadherence was associated with older age (14.6 years versus 13.0 years; $\mathrm{P}=0.04)$, longer disease duration ( 5.0 years versus 3.1 years; $\mathrm{P}=0.004)$ and reported use of herbal medications ( $40.0 \%$ versus $13.6 \%$; $\mathrm{P}=0.029)$. The most common reasons reported for missing medications were forgetfulness, feeling better and too many medications. In addition, patients reported being more likely to take anti-inflammatory medications and less likely to take herbal medicines.

CONCLUSION: Identified predictors of nonadherence such as age, disease duration and use of herbal treatments may enable the development of specific strategies to improve adherence in adolescents with IBD.
\end{abstract}

Key Words: Crohn's disease; Inflammatory bowel disease; Medication adherence; Pediatrics; Ulcerative colitis

\section{Les prédicteurs d'observance de la médication chez des patients pédiatriques atteints d'une maladie inflammatoire de l'intestin au Stollery Children's Hospital}

HISTORIQUE : Souvent, les personnes atteintes d'une maladie inflammatoire de l'intestin (MII) ne prennent pas leurs médicaments tels qu'ils leur sont prescrits.

OBJECTIF : Examiner les taux d'observance autodéclarés chez des patients atteints d'une MII du Stollery Children's Hospital d'Edmonton, en Alberta, et déterminer les prédicteurs d'observance des médicaments.

MÉTHODOLOGIE : On a posté un sondage à 212 patients pédiatriques atteints d'une MII du Stollery Children's Hospital. On a effectué une étude des dossiers des patients qui ont remis le sondage.

RÉSULTATS : Au total, 119 patients ont répondu au sondage. Les nonrépondants étaient beaucoup plus âgés que les répondants (14,5 ans par rapport à 13,2 ans, $\mathrm{P}=0,032$ ). Le taux d'observance totale s'établissait à $80 \%$. La non-observance s'associait à l'âge (14,6 ans par rapport à 13,0 ans, $\mathrm{P}=0,04)$, à une plus longue durée de la maladie $(5,0$ ans par rapport à 3,1 ans, $\mathrm{P}=0,04)$ et à l'utilisation déclarée de plantes médicinales $(40,0 \%$ par rapport à 13,6\%, $\mathrm{P}=0,029)$. Les principales raisons invoquées pour ne pas prendre les médicaments étaient l'oubli, le fait de se sentir mieux et le fait de prendre trop de médicaments. De plus, les patients ont déclaré être plus susceptibles de prendre des médicaments anti-inflammatoires et moins susceptibles de prendre des plantes médicinales.

CONCLUSION : Les prédicteurs établis de non-observance comme l'âge, la durée de la maladie et le recours à des plantes médicinales peuvent favoriser l'élaboration de stratégies précises pour améliorer l'observance des adolescents atteints d'une MII.

$\mathrm{T}_{\mathrm{b}}^{\mathrm{h}}$ he systemic sequelae and chronic nature of inflammatory bowel disease (IBD) often require the use of multiple medications. Polypharmacy includes anti-inflammatory and/or disease-modifying agents such as mesalamine, corticosteroids, azathioprine and methotrexate. Additional treatments include antibiotics, nutritional therapy with prescribed dietary modification, and micronutrient supplementation such as iron and vitamins. In addition, studies have shown that $41 \%$ to $72 \%$ of children and adolescents with IBD are also given complementary and alternative medicines such as fish oil, herbal medicines and other homeopathic treatments by their caregivers $(1,2)$. Therefore, IBD patients are required to follow a complicated management plan that most often involves taking a large number of pills each day.

Adherence is defined as the degree to which a patient cooperates with health care providers' advice regarding their medical treatment. This can include taking medications, as well as frequency of attendance at appointments and requested laboratory visits (3). The word adherence is used rather than compliance because it implies a collaborative approach to patient care (4). Adherence can be measured by a variety of methods including verbal reports, pill counts, pharmacy reports, urine or blood assays, and electronic medication dispensers. Although verbal reports may overestimate adherence, they are less costly, easier to implement and have been proven effective (5). Adherence to medication is important to treat acute exacerbations, maintain symptomatic remission, decrease disease activity and maintain adequate nutrition. In

${ }^{1}$ Inflammatory Bowel Disease Clinic, Division of Gastroenterology and Nutrition, Department of Paediatrics, Stollery Children's Hospital;

${ }^{2}$ Department of Pediatrics, University of Alberta, Edmonton, Alberta

Correspondence: Dr Hien Q Huynh, Pediatric Gastroenterology and Nutrition, Department of Pediatrics, Stollery Children's Hospital/University of Alberta, Aberhart Centre \# 1 Room 9219, 11402 University Avenue Northwest, Edmonton, Alberta T6G 2J3.

Telephone 780-407-3339, fax 780-407-3507, e-mail Hien.Huynh@ualberta.ca

Received for publication December 18, 2008. Accepted February 23, 2009 
TABLE 1

Patient characteristics - respondents versus nonrespondents

\begin{tabular}{lcc}
\hline Characteristic & $\begin{array}{c}\text { Respondents } \\
(\mathbf{n = 1 1 9 )}\end{array}$ & $\begin{array}{c}\text { Non- } \\
\text { respondents } \\
(\mathbf{n}=93)\end{array}$ \\
\hline Female sex, \% & 44.5 & 45.2 \\
Age, years (mean $\pm \mathrm{SD})^{*}$ & $13.2 \pm 3.40$ & $14.5 \pm 3.34$ \\
Disease type, \% & & \\
Crohn's disease & 56.3 & 55.9 \\
Ulcerative colitis & 39.5 & 37.6 \\
Indeterminate colitis & 4.2 & 6.5 \\
Disease duration, years (mean \pm SD) & $3.46 \pm 2.62$ & $3.50 \pm 2.77$ \\
\hline
\end{tabular}

${ }^{*} P=0.032$

fact, adherence has been shown to reduce the rates of poor treatment outcome by $26 \%$ (6). However, many patients do not follow the treatment plan prescribed by their physician. The nonadherence rate has been reported to be as high as $40 \%$ for short-term and $72 \%$ for long-term treatment regimens (5). Low adherence can lead to increased morbidity and hospitalization, increased health care spending, absence from school, extracurricular and social activities, and an overall decrease in quality of life (6). There are many factors that have been shown to contribute to patient adherence, such as medication type and dose, disease duration and severity, and medication side effects (7-11). Support systems, parental involvement, patient-physician communication and personal understanding of illness also play a role (6).

The aims of the present study were to determine the adherence rates of pediatric IBD patients at the Stollery Children's Hospital (Edmonton, Alberta) and the predictors of medication adherence. Adherence to anti-inflammatory medications versus micronutrient supplementation and complementary medicines were also examined.

\section{Participants}

\section{METHODS}

All pediatric IBD patients at the Stollery Children's Hospital were invited to participate in the study. A total of 212 patients were mailed a survey, of which 119 were completed and returned during the allotted study time period (respondents). Six respondents were partially excluded from the analysis because they chose not to specify their adherence rate. The study was approved by the University of Alberta Health Research Ethics Board (Edmonton, Alberta).

\section{Protocol}

A recently published questionnaire (10) with 24 domains was adapted for pediatric patients. The survey queried patient demographics as well as medication adherence to anti-inflammatory medications, micronutrient supplements and complementary medicines. Questions were designed to determine frequency and reasons for nonadherence to each type of medication. In addition, the survey asked questions regarding overall health awareness and communication.

The survey was mailed to all 212 patients who were entered in the Stollery Children's Hospital IBD database between May and August 2008. Patients who did not return the survey by mail were asked to complete the survey in the waiting room of
TABLE 2

Demographic and disease-related characteristics

\begin{tabular}{lcc}
\hline & \multicolumn{2}{c}{ Group } \\
\cline { 2 - 3 } Characteristic & $\begin{array}{c}\text { Adherent } \\
(\mathbf{n}=95)\end{array}$ & $\begin{array}{c}\text { Nonadherent } \\
(\mathbf{n}=\mathbf{1 8})\end{array}$ \\
\hline Female sex & 43.2 & 55.6 \\
Age, years (mean $\pm \mathrm{SD})^{\star}$ & $12.96 \pm 3.48$ & $14.55 \pm 2.94$ \\
Caucasian $^{\star}$ & 79.0 & 72.2 \\
English as first language & 96.8 & 94.4 \\
Urban residence $^{\dagger}$ & 64.2 & 61.1 \\
Postsecondary education of parent or guardian & 85.7 & 66.7 \\
Inflammatory bowel disease type $_{\quad}$ & \\
$\quad$ Crohn's disease & 62.1 & 33.3 \\
$\quad$ Ulcerative colitis & 35.8 & 50.0 \\
Disease duration, years (mean $\pm \mathrm{SD}$ ) & $3.1 \pm 2.38$ & $5.0 \pm 3.17$ \\
Surgeries & 17.9 & 11.1 \\
\hline
\end{tabular}

Data are presented as \% unless indicated otherwise. ${ }^{*} P=0.04 ;{ }^{*} P=0.004$. ${ }^{\dagger}$ Metropolitan Edmonton, Alberta

the IBD clinic. Patients completed the survey voluntarily and gave informed consent.

A chart review was completed to verify IBD diagnosis, disease duration, physician consistency and the physician's global assessment of disease severity using the Pediatric Crohn's Disease Activity Index (12) or criteria for evaluating the severity of ulcerative colitis (13). The number of medical appointments with a gastroenterologist in the past year (June 2007 to July 2008) was determined for each patient using the pediatric booking clinic patient database.

Data were also collected from the IBD patient database for subjects who did not respond to the survey and were designated as nonrespondents. Age, sex, disease type and duration were collected to determine whether there were any significant differences between the respondents and nonrespondents.

Overall, adherence rate was determined using a measure of adherence defined by reporting having taken medications as prescribed more than $80 \%$ of the time.

Results were analyzed using the STATA (StataCorp, USA) and SPSS (SPSS Inc, USA) statistical software packages for Windows (Microsoft Corporation, USA).

\section{RESULTS}

A total of 119 patients completed the survey - a 56\% response rate. Compared with respondents, the nonrespondents were not significantly different in sex, disease duration or type. However, nonrespondents were significantly older than respondents ( 14.5 years versus 13.2 years, respectively; $\mathrm{P}=0.032$ ) (Table 1).

The overall adherence rate determined by the survey was $79.8 \%$. Demographic- and disease-related characteristics of the adherent and nonadherent patients are summarized in Table 2. Compared with adherent patients, nonadherent patients were not significantly different in sex, place of residence (city versus rural), ethnicity or first language. Nonadherent patients were significantly older than adherent patients, with a mean age of 14.6 years versus 13.0 years $(\mathrm{P}=0.04)$. Nonadherent patients had a mean disease duration of 5.0 years versus 3.1 years for adherent subjects $(\mathrm{P}=0.004)$. A diagnosis of colitis was associated with nonadherence; however, when indeterminate colitis was removed from analysis, these results were no longer significant. There was a trend 
TABLE 3

Percentage of adherent and nonadherent patients taking each type of medication

\begin{tabular}{|c|c|c|c|}
\hline \multirow[b]{2}{*}{ Medication } & \multicolumn{2}{|c|}{ Group, \% } & \multirow{2}{*}{$\begin{array}{c}\text { Patients } \\
\text { taking } \\
\text { medication, } \mathrm{n}\end{array}$} \\
\hline & Adherent & Nonadherent & \\
\hline \multicolumn{4}{|l|}{ Prescription } \\
\hline Oral steroids & 19.0 & 5.56 & 19 \\
\hline Steroid enemas & 3.16 & 0.00 & 3 \\
\hline Mesalamine & 42.1 & 55.6 & 50 \\
\hline Mesalamine enemas & 10.5 & 5.56 & 11 \\
\hline Sulfasalazine & 21.1 & 11.1 & 22 \\
\hline Azathioprine* & 46.3 & 22.2 & 48 \\
\hline Methotrexate & 3.16 & 0.00 & 3 \\
\hline Infliximab & 12.6 & 0.00 & 12 \\
\hline Antibiotics & 15.8 & 5.56 & 16 \\
\hline Other & 6.32 & 0.00 & 6 \\
\hline \multicolumn{4}{|c|}{ Vitamins/micronutrients/complementary } \\
\hline Multivitamin & 56.8 & 50.0 & 63 \\
\hline Vitamin D & 57.9 & 38.9 & 62 \\
\hline Iron & 52.6 & 33.3 & 56 \\
\hline Calcium & 40.0 & 38.9 & 45 \\
\hline Fish oil & 10.5 & 5.56 & 11 \\
\hline Herbals** & 6.32 & 22.2 & 10 \\
\hline $\begin{array}{l}\text { Other (nutritional therapy, } \\
\text { probiotics, other vitamins } \\
\text { and micronutrients) }\end{array}$ & 19.0 & 11.1 & 20 \\
\hline Total & & & 119 \\
\hline
\end{tabular}

${ }^{\star} P=0.048 ;{ }^{*} P=0.029$

toward nonadherence in individuals with an education level of high school or lower compared with those who had a postsecondary education; however, these results were not statistically significant (31.2\% versus $13.2 \%$, respectively; $\mathrm{P}=0.075$ ).

Self-reported medication use in the previous three months was found to affect adherence. Forty-one per cent of patients reported taking azathioprine. This group had a $91.7 \%$ adherence rate, compared with $78.5 \%$ for those not reporting taking azathioprine $(\mathrm{P}=0.048)$. Ten per cent of patients reported taking infliximab and this was also associated with a higher adherence rate $(100 \%)$ compared with $82.2 \%$ for subjects not taking infliximab. On the other hand, the reported use of herbal medications was found to predict nonadherence (40\% versus $13.6 \% ; \mathrm{P}=0.029)$. Table 3 summarizes the percentage of patients in both the adherent and nonadherent groups who reported taking each type of medication, as well as the total number of patients taking each type of medication.

The two most common reasons reported for nonadherence included being too busy $(55.6 \%)$ and that the medications were difficult to swallow $(17.8 \%)$. In addition, $16.7 \%$ of patients who were prescribed enemas admitted to not taking them, with the most common reason being that they were uncomfortable with them $(18.2 \%)$. Nonadherence to prescribed vitamins was reported by $46.6 \%$ of patients, with the most common reasons being that they were too busy $(44 \%)$, it involved too many pills (28\%), and they made them feel sick (24\%). Finally, $21.0 \%$ of patients reported not taking herbal remedies or complementary medicines because they did not believe they worked $(37.5 \%)$, there were too many medicines
TABLE 4

Univariate predictors of nonadherence $(n=119)$

\begin{tabular}{|c|c|c|c|}
\hline \multirow[b]{2}{*}{ Variable } & \multicolumn{2}{|c|}{ Group } & \multirow[b]{2}{*}{$\mathbf{P}$} \\
\hline & Nonadherent & Adherent & \\
\hline Overall adherence rate, $\%$ & \multicolumn{2}{|c|}{79.8} & \\
\hline \multicolumn{4}{|l|}{ Predictors of nonadherence } \\
\hline Older age, years (mean \pm SD) & $14.6 \pm 2.94$ & $13.0 \pm 3.48$ & 0.04 \\
\hline $\begin{array}{l}\text { Longer disease duration, years } \\
\quad(\text { mean } \pm \mathrm{SD})\end{array}$ & $5.0 \pm 3.17$ & $3.1 \pm 2.38$ & 0.004 \\
\hline Use of herbal medications, $\%$ & 40.0 & 13.6 & 0.029 \\
\hline $\begin{array}{l}\text { Appointments in past year, } \\
\text { mean } \pm S D\end{array}$ & $1.61 \pm 0.98$ & $4.03 \pm 3.05$ & 0.001 \\
\hline
\end{tabular}

(25\%) or they were too busy $(20.8 \%)$. Overall, the most common reasons reported for missing any type of medication were forgetfulness $(56.3 \%)$, feeling better $(16.0 \%)$ and too many medications $(13.4 \%)$. In addition, patients were most likely to take anti-inflammatory medications $(61.3 \%)$ and least likely to take herbal medicines $(44.9 \%)$. Medication reminders from another individual or the use of devices (eg, pill counters) had no effect on adherence.

The average number of gastroenterology appointments in the past year (July 2007 to June 2008) was found to predict adherence. Adherent patients reported seeing their gastroenterologist more often than nonadherent patients $(\mathrm{P}=0.006)$. These results were confirmed by chart review, which revealed, on average, 4.0 appointments/year in the adherent group versus 1.6 appointments/year in the nonadherent group $(\mathrm{P}=0.001)$. However, seeing a family doctor for a yearly check-up was not related to adherence. Physician consistency, defined as seeing the same gastroenterologist for $75 \%$ or more of the past four clinic visits, occurred for only $47.8 \%$ of patients but was not found to affect adherence. Physician-rated disease severity was found to be consistently less severe than the patient self-rated severity for both the most recent $(\mathrm{P}=0.005)$ and most common $(\mathrm{P}=0.002)$ physician ratings over the past year (July 2007 to June 2008). Predictors of nonadherence are summarized in Table 4.

\section{DISCUSSION}

The results of the present cross-sectional study suggest that medication adherence is quite high in pediatric IBD patients at the Stollery Children's Hospital. The self-reported adherence rate of $79.8 \%$ was higher than expected based on other published rates, which average approximately $50 \%$ in children and, often, much lower in adolescents $(9,14)$. While this finding could indicate that our patient population is more adherent than others, it is more likely a reflection of the adherence rate of those who responded to the survey. It is notable that we found nonrespondents to this survey were significantly older than respondents. Because older age was significantly associated with nonadherence in the respondent group, this finding could indicate that many of the nonadherent patients, who were older as a group, were not motivated to complete the survey.

Demographic and disease-related predictors of nonadherence reported in the literature are quite varied. The finding of the predictive value of older adolescence on nonadherence coincides with the results of other published data $(6,8)$. 
Adherence is believed to be lowest during adolescence for a variety of reasons including embarrassment, peer influence and fear of stigmatization, and a sense of immortality. The effect of adverse outcomes on body image, such as weight gain and acne with oral steroids, may also contribute to poor adherence $(8,15)$. Rebellion and the struggle for autonomy as well as decreased parental influence on behaviour may also contribute to decreased adherence in adolescence. Increased disease duration has also been found to predict nonadherence. This result conflicts with other published data that suggest nonadherence is predicted by shorter disease duration $(10,11)$ or that duration has no effect on adherence (5). Although a recent diagnosis could coincide with lack of knowledge and routine, thus leading to nonadherence in our pediatric population, we found that older age and longer duration of disease were associated with nonadherence. This often coincides with patients entering adolescence who may struggle with increased autonomy as they prepare to transition to adult care, which may contribute to nonadherence.

We identified an interesting trend toward nonadherence in those with a parent or guardian education level of high school or lower. This finding could be due to a decreased understanding of the disease and the importance of medication use in prevention of adverse outcomes. Socioeconomic status and the effect of medication and appointment transportation costs in this demographic group may also be other contributing factors; however, these factors were not assessed in the present study. Demographic and disease-related characteristics such as sex and disease severity have been shown to affect adherence $(3,11)$, but these findings were not supported by our study.

The type and number of medications prescribed, and number of daily doses have been documented to affect adherence $(9,16)$. In our study, patients taking azathioprine were more likely to be in the adherent group versus the nonadherent group, which contradicts other published data (3). However, the number of daily doses and disease severity were not reported to affect adherence by our patient population. Nevertheless, because azathioprine is taken only once daily, it could be a contributing factor to increased adherence with this type of medication. Infliximab was also found to predict adherence, which could be explained by the fact that this medication is administered as an infusion received in a clinic at eight-week intervals. Therefore, the number of doses and method of drug administration could indirectly affect adherence in our patient population.

Studies have shown that $41 \%$ to $72 \%$ of children and adolescents with IBD report using complementary and alternative medicines (CAMs) that may include herbal medicines, megavitamins, nutritional therapy, fish oils, probiotics and other alternatives as part of their treatment regimen $(1,2)$. In our patient population, $8.4 \%$ of patients reported using herbal medicines and $10.1 \%$ reported using fish oils. In our study, the use of herbal medicines was found to predict nonadherence. This finding is likely a reflection of these patients' and/or their caregivers' lack of confidence in, or distrust of, the effectiveness of traditional medications. Patients may take CAMs for a variety of other reasons including parental use, side effects from prescription medications, increased autonomy, or desperation and hopefulness for a cure $(1,2)$. In addition, one observational study (17) found that $71 \%$ of caregivers chose unsuitable nonprescription medications for their children. Although this statistic does not refer specifically to herbal medicines, it indicates the importance of patient education. Due to the increase of nonadherence in patients using herbal medicines, it is important for physicians to be aware of patients' CAM use, and to educate them on possible drug interactions and the importance of maintaining the continuous use of prescription medications.

The number of yearly appointments with a gastroenterologist was also found to predict medication adherence. Although other published data report a lack of correlation between appointment-keeping behaviour and medication adherence in adult patients with hypertension (18), our results have shown that adherent patients reported seeing their gastroenterologist more frequently than nonadherent patients. Furthermore, a chart review confirmed that patients who reported themselves to be adherent saw their gastroenterologist more frequently than those who were nonadherent. Therefore, although patients may be in remission, more frequent visits may be warranted to encourage continuous use of medications and to prevent disease exacerbations.

The most common reasons reported for nonadherence were forgetfulness, feeling better and having to take too many medicines. Because reminders by other individuals or devices, such as a clock or notes, had no effect on adherence, this may indicate that better mechanisms are needed to decrease patient forgetfulness. Although the number of medications prescribed and the number of daily doses were not shown to statistically affect adherence, patients commonly stated too many medicines as a reason for nonadherence. Decreasing the number of medicines and supplements prescribed, as well as prescribing medicines with fewer daily doses, may increase patient adherence to medication. In fact, newer formulations of mesalamine have been developed with this in mind. A multimatrix release mesalamine with a higher dose of mesalamine per pill has been approved at once-daily dosing, which is expected to increase adherence rates over time (19).

Potential weaknesses of the present study include a small sample size and the survey method of assessment, which has been shown to overestimate adherence. Despite these limitations, however, we have identified key areas for further investigation and the targeted development of strategies to improve adherence in the pediatric IBD population. In particular, this includes studies targeting the adolescent population and appropriate tools for parental education. Based on the results of the present study and other published data, there is a need for further investigation to determine other factors that influence medication adherence. In organ transplant patients, the transition to adult services was found to be associated with decreased adherence. In fact, adherence in transitioned adolescent liver transplant patients was found to be significantly lower than in adolescent patients who remain under pediatric care (20). Also, because $54 \%$ of patients in the adult IBD clinic in Edmonton, Alberta, have admitted that they miss taking their medicines (21), it can be hypothesized that medication adherence rates may decrease in adolescent IBD patients as they transition to adult care - an area that clearly requires further investigation. The effects of psychological stability, parental marital status and family income on adherence are also factors that may be barriers to adherence. In 
addition, because nonadherence has been shown to relate to poorer patient quality of life, this may be an area for further investigation in our patient population (14).

\section{CONCLUSION}

Pediatric IBD patients at the Stollery Children's Hospital report a $79.8 \%$ adherence rate. Identified predictors of nonadherence such as age, disease duration and use of herbal treatments may enable us to develop specific strategies to improve adherence in this population. In particular, targeted strategies for the adolescent age group seem to be warranted.

\section{REFERENCES}

1. Day AS, Whitten KE, Bohane TD. Use of complementary and alternative medicines by children and adolescents with inflammatory bowel disease. J Paediatr Child Health 2004:40:681-4

2. Heuschkel R, Afzal N, Wuerth A, et al. Complementary medicine use in children and young adults with inflammatory bowel disease. Am J Gastroenterol 2002;97:382-8.

3. Bernal I, Domenech E, Garcia-Planella, et al. Medication-taking behavior in a cohort of patients with inflammatory bowel disease. Dig Dis Sci 2006;51:2165-9.

4. Sewitch MJ, Leffondre K, Dobkin PL. Clustering patients according to health perceptions: Relationships to psychosocial characteristics and medication nonadherence. J Psychosom Res 2004;56:323-32.

5. Ediger JP, Walker JR, Graff L, et al. Predictors of medication adherence in inflammatory bowel disease. Am J Gastroenterol 2007;102:1417-26.

6. Taddeo D, Egedy M, Frappier J-Y. Adherence to treatment in adolescents. Paediatr Child Health 2008;13:19-24.

7. Sewitch MJ, Abrahamowicz M, Barkun A, et al. Patient nonadherence to medication in inflammatory bowel disease. Am J Gastroenterol 2003;98:1535-44.

8. Matsui D. Current issues in pediatric medication adherence. Paediatr Drugs 2007;9:283-8.

9. Oliva-Hemker MM, Abadom V, Cuffari C, Thompson RE. Nonadherence with thiopurine immunomodulator and mesalamine medications in children with Crohn disease. J Pediatr Gastroenterol Nutr 2007;44:180-4.

10. D'Inca R, Bertomoro P, Mazzocco K, Vettorato MG, Rumiati R, Sturniolo GC. Risk factors for non-adherence to medication in inflammatory bowel disease patients. Aliment Pharmacol Ther 2008;27:166-72.

11. Hawthorne AB, Rubin G, Ghosh S. Review article: Medication non-adherence in ulcerative colitis - strategies to improve adherence with mesalazine and other maintenance therapies. Aliment Pharmacol Ther 2008;27:1157-66.

12. Hyams JS, Ferry GD, Mandel FS, et al. Development and validation of a pediatric Crohn's disease activity index. J Pediatr Gastroenterol Nutr 1991;12:439-47.

13. Truelove SC, Witts LJ. Cortisone in ulcerative colitis: Final report on a therapeutic trial. Br Med J 1955;2:1041-8.

14. Hommel KA, Davis CM, Baldassano RN. Medication adherence and quality of life in pediatric inflammatory bowel disease. J Pediatr Psychol 2008;33:867-74.

15. Zelikovsky N, Schast AP, Palmer J, Meyers KE. Perceived barriers to adherence among adolescent renal transplant candidates. Pediatr Transplant 200812:300-8.

16. Cerveny P, Bortlik M, Kubena A, Vlcek J, Lakatos PL, Lukas M. Nonadherence in inflammatory bowel disease: Results of factor analysis. Inflamm Bowel Dis 2007;13:1244-9.

17. Eiland LS, Salazar ML, English TM. Caregivers' perspectives when evaluating nonprescription medication utilization in children. Clin Pediatr (Phila) 2008;47:578-87.

18. Ogedegbe G, Schoenthaler A, Fernandez S. Appointment-keeping behavior is not related to medication adherence in hypertensive African Americans. J Gen Intern Med 2007;22:1176-9.

19. Kedia P, Cohen RD. Once-daily MMX mesalamine for the treatment of mild-to-moderate ulcerative colitis. Ther Clin Risk Manag 2007;3:919-27.

20. Annunziato RA, Emre S, Shneider B, Barton C, Dugan CA, Shemesh E. Adherence and medical outcomes in pediatric liver transplant recipients who transition to adult services. Pediatr Transplant 2007;11:608-14.

21. Waters BM, Jensen L, Fedorak RN. Effects of formal education for patients with inflammatory bowel disease: A randomized controlled trial. Can J Gastroenterol 2005;19:235-44. 


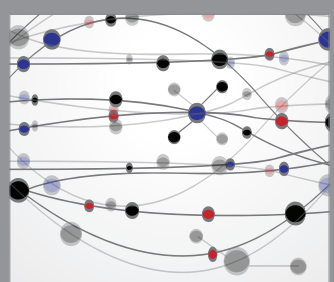

The Scientific World Journal
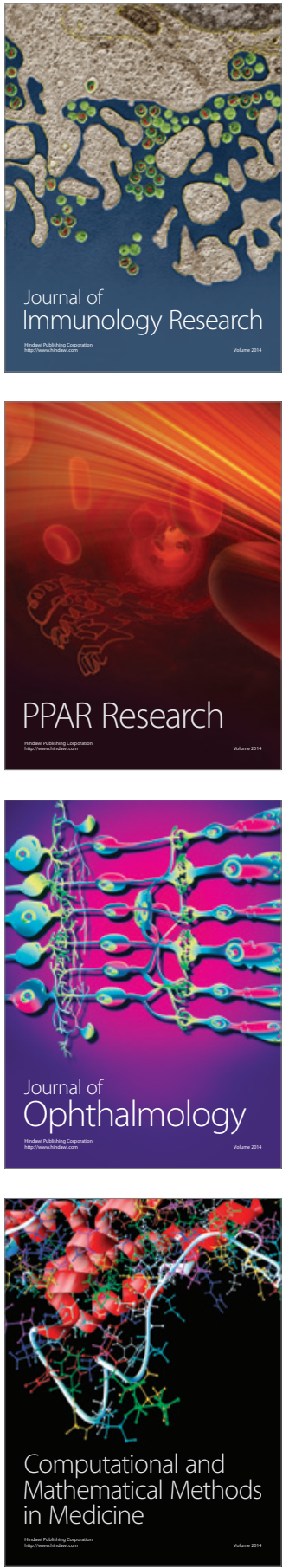

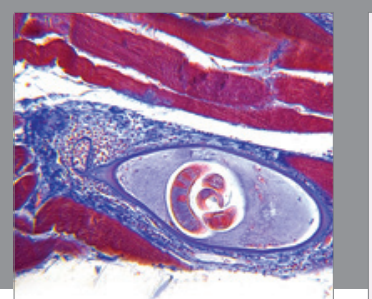

Gastroenterology Research and Practice

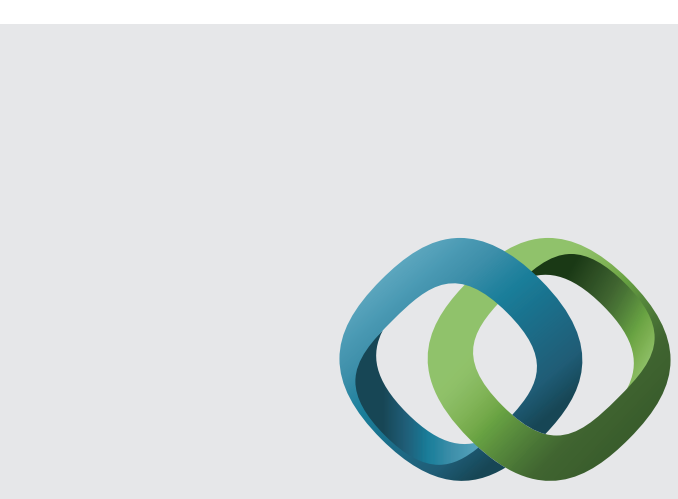

\section{Hindawi}

Submit your manuscripts at

http://www.hindawi.com
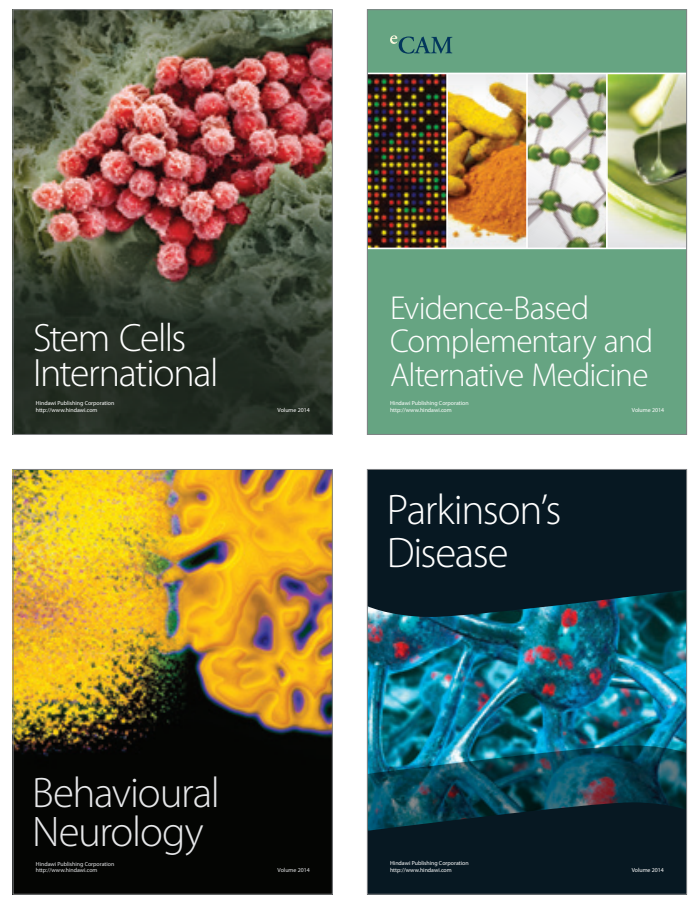
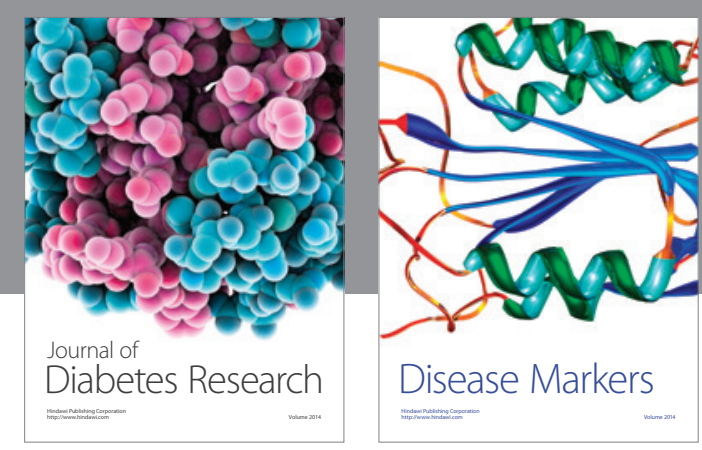

Disease Markers
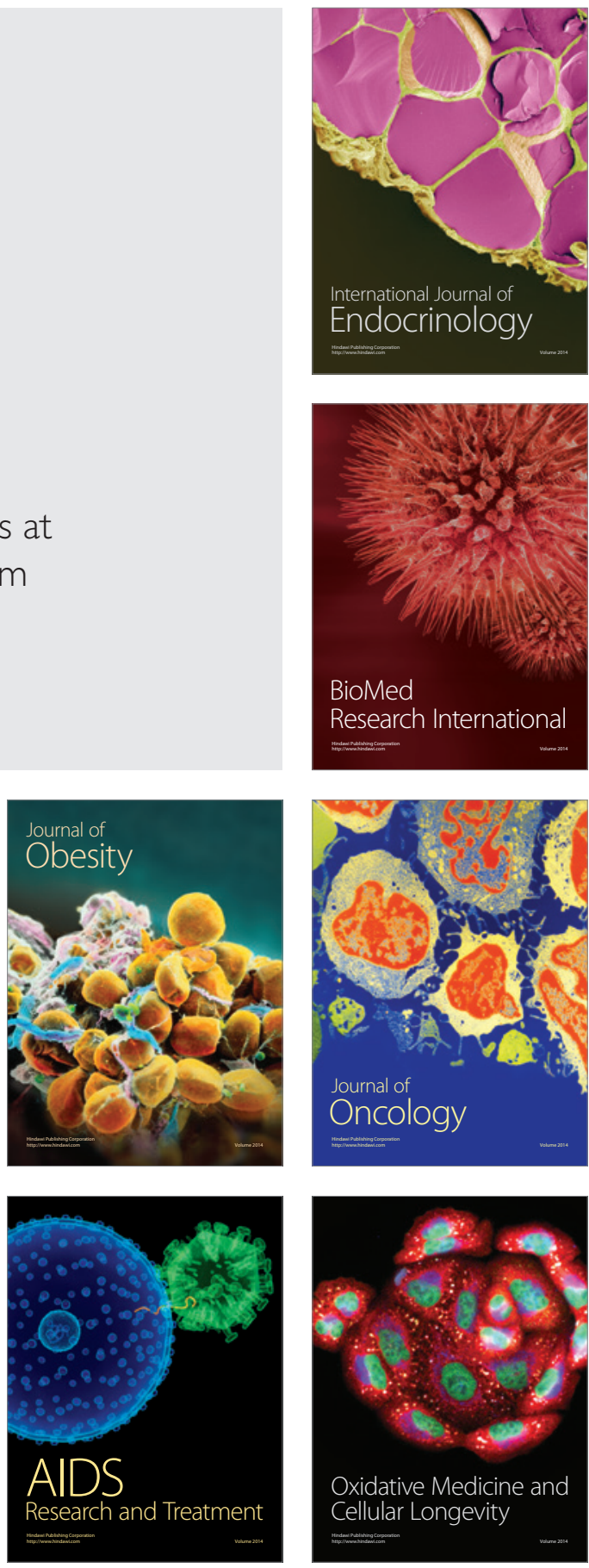